\title{
Processing dynamic split Hopkinson three-point bending test with normalized specimen of quasi-brittle material
}

\author{
Jean-Luc Hanus ${ }^{1, a}$, Benoît Magnain ${ }^{1}$, Bastien Durand ${ }^{2}$, Javier Alanis-Rodriguez ${ }^{2}$ \\ AND PATRICE BAILlY ${ }^{1}$ \\ 1 PRISME Laboratory, Loire Valley University, ENSI de Bourges, 88 boulevard Lahitolle, 18020 Bourges Cedex, France \\ 2 PRISME Laboratory, Loire Valley University, ENSI Bourges, INERIS Parc Technologique Alata, 60550 Verneuil en Halatte, \\ France
}

Received 10 February 2012, Accepted 19 September 2012

\begin{abstract}
Evaluation of the dynamic properties of quasi-brittle materials is of the utmost importance for assessing the vulnerability of structural components under dynamic loadings such as collision or explosion. To investigate the dynamic strength of (quasi)-brittle material, three-point bending tests are performed on a modified Split Hopkinson Pressure Bar. Such an apparatus is often used with pre-cracked specimen to determine the dynamic stress intensity factor of metallic materials. With quasi-brittle materials special care has to be paid to the processing of the test since fracture can occur at very low strains. The specimen remains in an out-of equilibrium state and fracture occurs before the support reactions appear as if it was a support-free impact test. A special non-equilibrium analytical approach has been developed to process the tests. Finite-element simulations are used to assess relevance of the proposed analysis for normalized short beams. Experimental results on brick and concrete samples showing a significant dynamic strength increase are presented.
\end{abstract}

Key words: Dynamic bending / out-of-equilibrium state / beam model / finite-element / SHPB / brittle material / dynamic increase factor

\begin{abstract}
Résumé - Dépouillement d'un essai de flexion dynamique aux barres de Hopkinson sur un matériau quasi-fragile. Le dispositif des barres de Hopkinson constitue le standard pour évaluer les propriétés dynamiques de matériaux à de hautes vitesses de déformation. Son adaptation pour la réalisation d'essais de flexion permet d'étudier l'effet de la vitesse sur la résistance en traction de matériaux quasifragiles. Pour ces matériaux, la rupture apparaît pour de faibles déformations et avant atteinte d'un état d'équilibre dans l'échantillon. Une procédure d'analyse hors d'équilibre de l'essai a été développée. Des simulations numériques par éléments-finis permettent d'en évaluer la pertinence pour des échantillons peu élancés. Des résultats d'essais sur des échantillons de brique et de béton illustrent l'augmentation de résistance en traction avec la vitesse d'impact.
\end{abstract}

Mots clés : Flexion dynamique / réponse hors équilibre / modélisation poutre / simulations EF / barres de Hopkinson / matériau quasi-fragile / facteur d'amplification dynamique

\section{Introduction}

Safety analysis of structural systems need to address a wide range of malevolent attacks or accident scenarios. Due to the extreme nature of blast or impact loadings, the deformation and fracture behavior of materials differ significantly to that observed under quasi-static conditions. Precise rate dependent material characteristics,

\footnotetext{
a Corresponding author:

jean-luc.hanus@ensi-bourges.fr
}

used as constitutive models parameters, are required to perform accurate numerical simulations of the response of structures to transient loadings. At high strain rates, the strength of concrete or other concrete-like materials increases significantly. This increase is usually reported by defining a dynamic increase factor (DIF), i.e. the ratio of the dynamic to static strength, as function of strain rate $[1]$.

The quasi-static tensile strength of a geomaterial can be evaluated in several ways: direct tensile tests or 


\section{Nomenclature}

\begin{tabular}{|c|c|}
\hline$a$ & Specimen thickness $(\mathrm{m})$ \\
\hline$b$ & Specimen width $(\mathrm{m})$ \\
\hline$A_{B}$ & Bars cross section $\left(\mathrm{m}^{2}\right)$ \\
\hline$C_{B}$ & Uniaxial elastic wave celerity $\left(\mathrm{m} \cdot \mathrm{s}^{-1}\right)$ \\
\hline$C_{f}$ & Flexural wave celerity $\left(\mathrm{m} . \mathrm{s}^{-1}\right)$ \\
\hline$C_{p}$ & $\mathrm{P}$-wave celerity $\left(\mathrm{m} \cdot \mathrm{s}^{-1}\right)$ \\
\hline$D I F$ & Dynamic Increase Factor \\
\hline$E_{B}, E_{S}$ & Bars and specimen Young's moduli (GPa) \\
\hline$\varepsilon_{i}, \varepsilon_{r}$ & Incident and reflected strains in input bar \\
\hline$F_{C}$ & Force at input bar/specimen interface $(\mathrm{N})$ \\
\hline$\phi_{B}$ & Bars diameter $(\mathrm{m})$ \\
\hline$I$ & Specimen area moment of inertia $\left(\mathrm{m}^{4}\right)$ \\
\hline$L$ & Distance between supports $(\mathrm{m})$ \\
\hline$\lambda$ & Wavelength $(\mathrm{m})$ \\
\hline$L_{B}, L_{I}, L_{S}$ & Incident bar, striker and specimen lengths (m) \\
\hline$M$ & Bending moment (N.m) \\
\hline$\psi$ & Specimen cross section rotation (rad) \\
\hline$\rho_{B}, \rho_{S}$ & Bars and specimen densities $\left(\mathrm{kg} \cdot \mathrm{m}^{-3}\right)$ \\
\hline$\sigma_{y}$ & Specimen flexural strength (MPa) \\
\hline$t_{f}$ & Support reaction time $(\mathrm{s})$ \\
\hline$t_{r}$ & Fracture time $(\mathrm{s})$ \\
\hline$t_{t}$ & Transit time through thickness (s) \\
\hline$V_{c}$ & Velocity at input bar/specimen interface $\left(\mathrm{m} . \mathrm{s}^{-1}\right)$ \\
\hline$w$ & Specimen deflection $(\mathrm{m})$ \\
\hline$Z_{B}$ & Bars impedance (kg.s $\left.{ }^{-1}\right)$ \\
\hline
\end{tabular}

indirect tensile tests. The main advantages of the direct tensile test are a known and simple stress state and a stressing of the entire gage-section volume so that it appears to be the natural way to determine the strength or to obtain a complete stress-strain curve. However, this test, not standardized, is complexed to perform to guarantish a purely uniaxial tensile stress state in the gagesection without any perturbation from additional torsion or bending stress state. As a consequence, the tensile strength is often estimated from two indirect standardized tensile tests: the flexural tensile strength test and the Brazilian or splitting tensile strength test. The boundary conditions and specimen geometry induce an uniaxial tension in a portion of the specimen in a fairly simple manner so that these tests are easier to conduct and to control.

Split Hopkinson Pressure Bars (SHPB) experimental techniques have overcome limitations of conventional servo-hydraulic testing instrument or drop weight impact test at high strain rates [2]. The classical configuration, with a short specimen placed between long input and output bars, used to perform compression test, can be modified for the study of dynamic mechanical behavior in tension and torsion test [3]. To characterize the influence of the strain rate on the mechanical strength properties of geomaterials, different kinds of SHPB tests can be performed: direct tensile test, spall test, brazilian splitting test or bending test. If cylinder brazilian splitting test [4] and now spall test [5] are fairly common and well mastered, it is not the same for the bending test which is mainly used with pre-notched specimen to determine the fracture-toughness of materials [6]. Performing dynamic bending test, with a set-up consistant with the static one, will allow us to define a dynamic increase factor associated with flexural tensile strength.

SHPB bending test on quasi-brittle materials poses specific problems. Indeed, the classical analysis of a test is based on the knowledge of the stress and strain states of the specimen assuming a quasi-static equilibrium within the sample. For the quasi-brittle materials studied, fracture occurs well before such a state may be attained and at relatively low strains. Furthermore, all the tests performed correspond to the total fracture of the sample before a reaction appears on the supports. Test processing thus requires a pertinent dynamic model to perform a transient analysis. The proposed model takes into account the fact that the rupture appears for low strains and at the very beginning of the test. It is based on the use of a beam of a great length. It has been applied to very thin brick specimen (thickness $a=17 \times 10^{-3} \mathrm{~m}$ ) with a high twinge (length to thickness ratio $\frac{L_{S}}{a}=13$ ) [7]. In order to characterise the flexural strength increase, trials are underway on normalized samples with a greater thickness and a lower slenderness $[8,9]$ for which the validity of the proposed approach must be assessed.

The aim of this paper is to provide a comparative analysis of a test processing using the proposed analytical approach and numerical simulations by the finite-element method and to present experimental results on concretelike materials. The paper first presents the experimental 


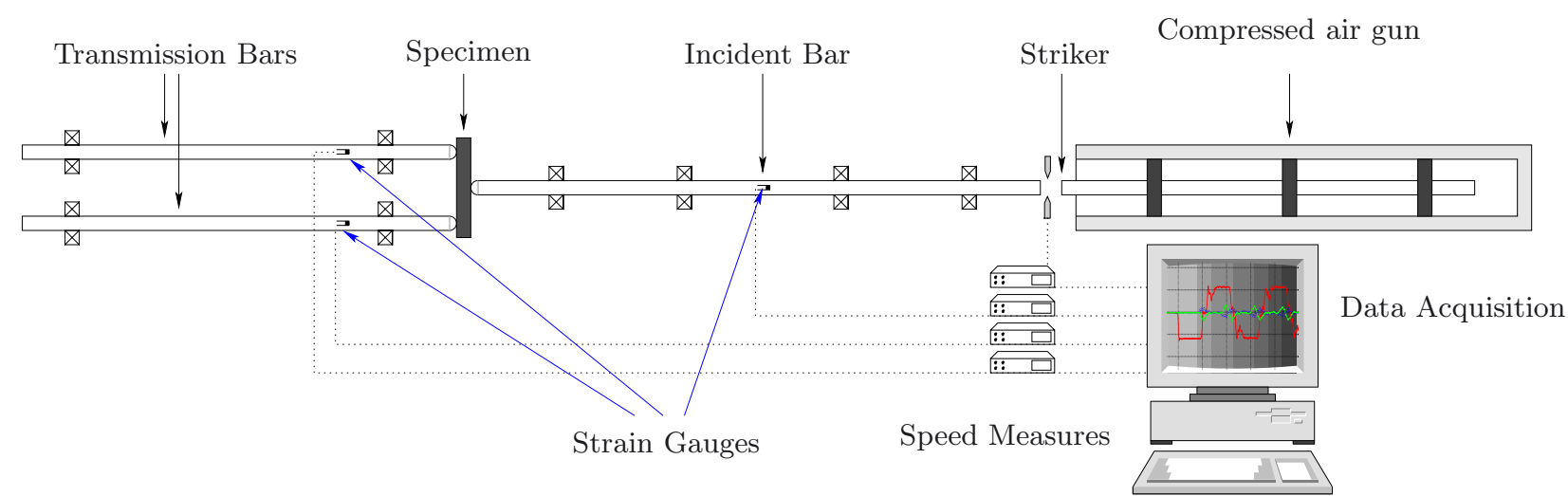

Fig. 1. SHPB 3-point bending test set-up.

Table 1. Characteristics of the SHPB system.

\begin{tabular}{cc}
\hline Striker length & $L_{I}=1.25 \mathrm{~m}$ \\
Incident bar length & $L_{B}=3 \mathrm{~m}$ \\
Bars diameter & $\phi_{B}=40 \times 10^{-3} \mathrm{~m}$ \\
Young's modulus & $E_{B}=74 \mathrm{GPa}$ \\
Density & $\rho_{B}=2800 \mathrm{~kg} \cdot \mathrm{m}^{-3}$ \\
Bars cross section & $A_{B}=1.23 \times 10^{-3} \mathrm{~m}^{2}$ \\
Elastic wave celerity & $C_{B}=5140 \mathrm{~m} \cdot \mathrm{s}^{-1}$ \\
Impedance & $Z_{B}=18094 \mathrm{~kg} \cdot \mathrm{s}^{-1}$ \\
\hline
\end{tabular}

set-up. The second part is dedicated to the major concern in processing SHPB experimental recordings. The third part describes the proposed transient beam analysis procedure. In a fourth part, a test with a brick sample is fully analyzed with the long beam model and the obtained results are compared with those of finite-element simulations. Finally, results of dynamic tensile strength enhancement with brick and concrete specimen are presented.

\section{Experimental set-up}

The modified SHPB apparatus for dynamic bending (Fig. 1 and Tab. 1) used in this study has been initially proposed by [10]. The apparatus is constituted of three bars: one input bar or incident bar used to apply the load and two output bars or transmission bars which also constitute specimen supports.

The impact velocity is measured via photoelectric cells. The strain waves in the bars are measured using resistance gauges. In order to enable an easy separation of the successively recorded incident and reflected waves, the gauges are glued in the middle of the incident bar. The raw data are pre-processed with DAVID software [11] taking into account wave dispersion in the bars.

Experiments are performed on brick and concrete specimen. The specimen geometries and material characteristics deduced from quasi-static instrumented three point bending tests are summarized in Table 2. A Poisson's ratio of 0.2 is assumed. The support length is small since: $3.5 a \leq L \leq 4 a$.

\section{Signal processing}

The impact velocity $V_{c}$ and force $F_{c}$ at the interface between incident bar and specimen are determined using the classical formulae of momentum conservation and kinematic compatibility condition:

$$
\begin{aligned}
& V_{c}(t)=-C_{B}\left(\varepsilon_{i}(t)-\varepsilon_{r}(t)\right) \\
& F_{c}(t)=-C_{B} Z_{B}\left(\varepsilon_{i}(t)+\varepsilon_{r}(t)\right)
\end{aligned}
$$

where $C_{B}=\sqrt{E_{B} / \rho_{B}}$ is the uniaxial wave speed and $Z_{B}=E_{B} A_{B} / C_{B}$ is the characteristic impedance and where $\varepsilon_{i}$ and $\varepsilon_{r}$ are the incident and the reflected waves at the input bar/specimen interface.

However, special precautions are required for processing the data. The strain gages record successively an incident and a reflected wave in the middle of the long incident bar (Fig. 1). These recorded pulses must be precisely synchronized and transported towards the specimen/bar interfaces. This operation can either be done by uniaxial wave transport or by simulating the elastic structural response of the specimen $[12,13]$.

SHPB dynamic tests differ from quasi-static ones in the sense that neither a controlled force nor a displacement are imposed. The loading results from dynamic interactions between the deformed specimen and the incident bar at contact zone. In bending tests, the elastic response of the test specimen viewed as a structure, which relates $V_{c}$ to $F_{c}$, determines the reflection of the compression wave and hence the loading conditions. This coupling relation can be formally written as:

$$
\mathscr{G}_{\tau \in[0, t]}\left(F_{c}(\tau), V_{c}(\tau)\right)=0
$$

The accuracy of calculated intrinsic characteristics such as the tensile strength of the material, depends mainly on two key points (Fig. 3):

- the wave synchronization and fictitious transport from the point of measure to the bar/specimen interface;

- the level of realism of the specimen model used to simulate the structural response.

In this paper, attention is focused on the second point. During the test, the specimen is subjected to an impact 
Table 2. Specimen characteristics.

\begin{tabular}{ccc}
\hline Material & brick & concrete \\
\hline Length & $L_{S}=22 \times 10^{-2} \mathrm{~m}$ & $L_{S}=16 \times 10^{-2} \mathrm{~m}$ \\
Thickness & $a=5.3 \times 10^{-2} \mathrm{~m}$ & $a=4 \times 10^{-2} \mathrm{~m}$ \\
Width & $b=5.3 \times 10^{-2} \mathrm{~m}$ & $b=4 \times 10^{-2} \mathrm{~m}$ \\
Young's modulus & $E=23 \mathrm{GPa}$ & $E=32 \mathrm{Gpa}$ \\
Density & $\rho=2080 \mathrm{~kg} . \mathrm{m}^{-3}$ & $\rho=2290 \mathrm{~kg} \cdot \mathrm{m}^{-3}$ \\
Distance between supports & $L=21 \times 10^{-2} \mathrm{~m}$ & $L=15 \times 10^{-2} \mathrm{~m}$ \\
Flexural strength & $\sigma_{y}=5.5 \mathrm{MPa}$ & $\sigma_{y}=7.5 \mathrm{MPa}$ \\
\hline
\end{tabular}

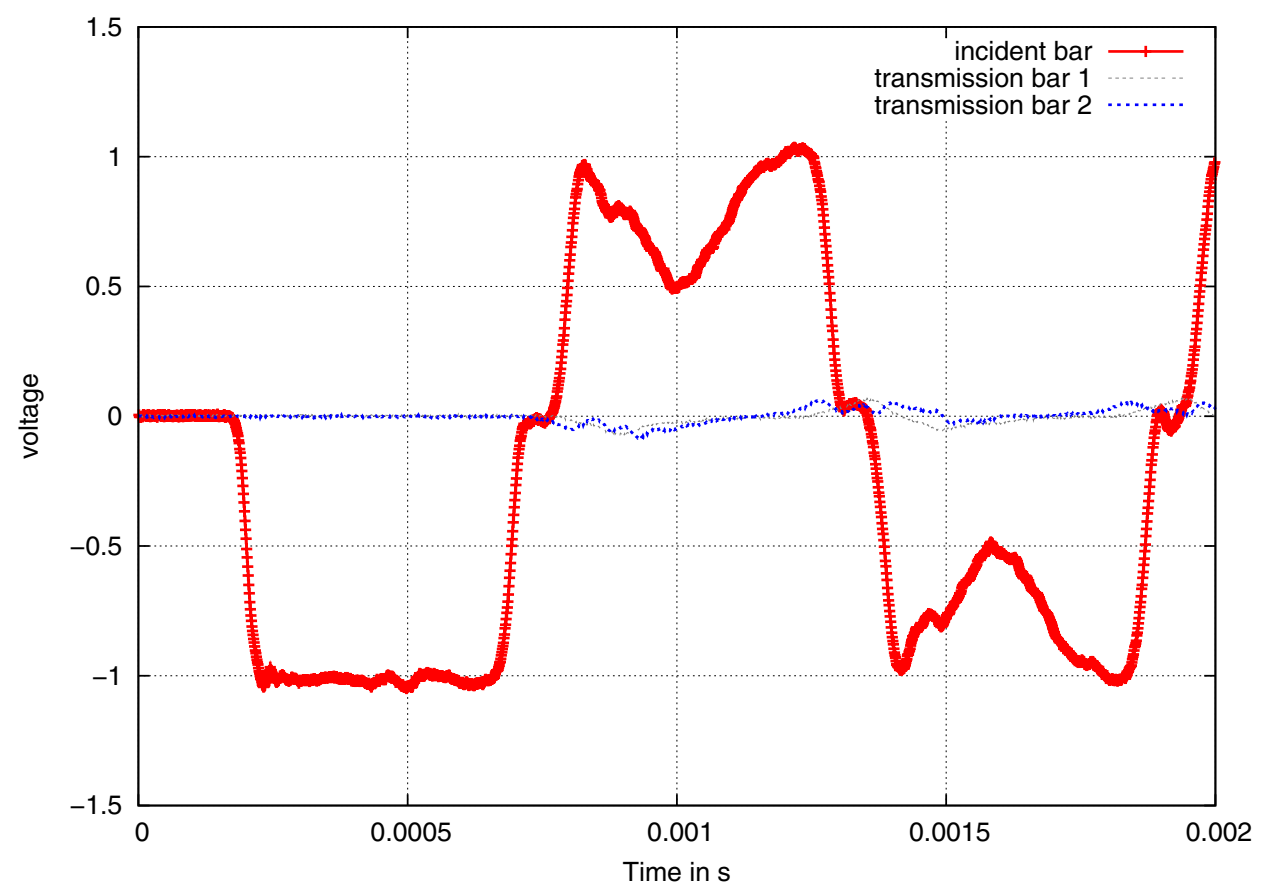

Fig. 2. Raw signals measured.

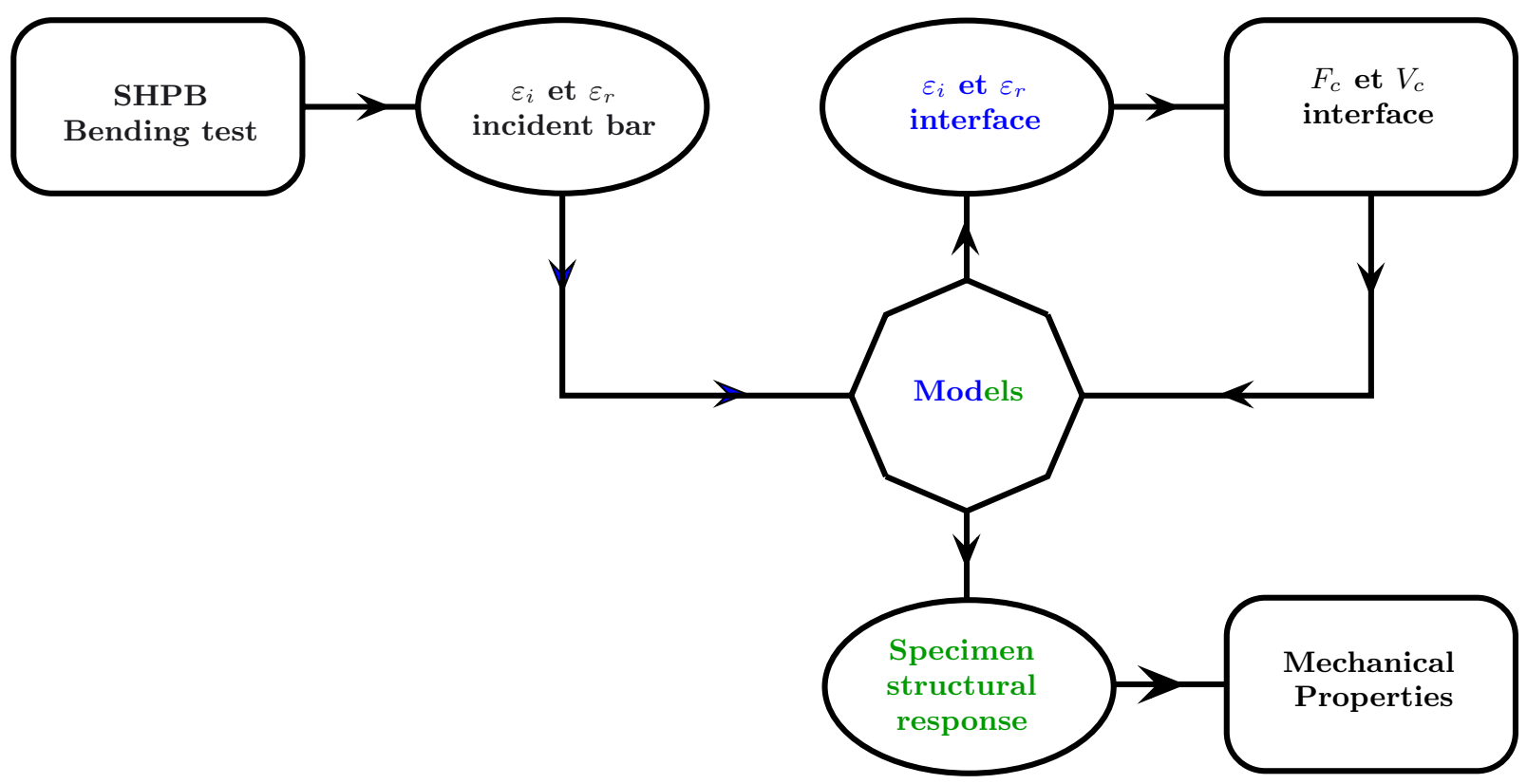

Fig. 3. Key points in test analysis. 


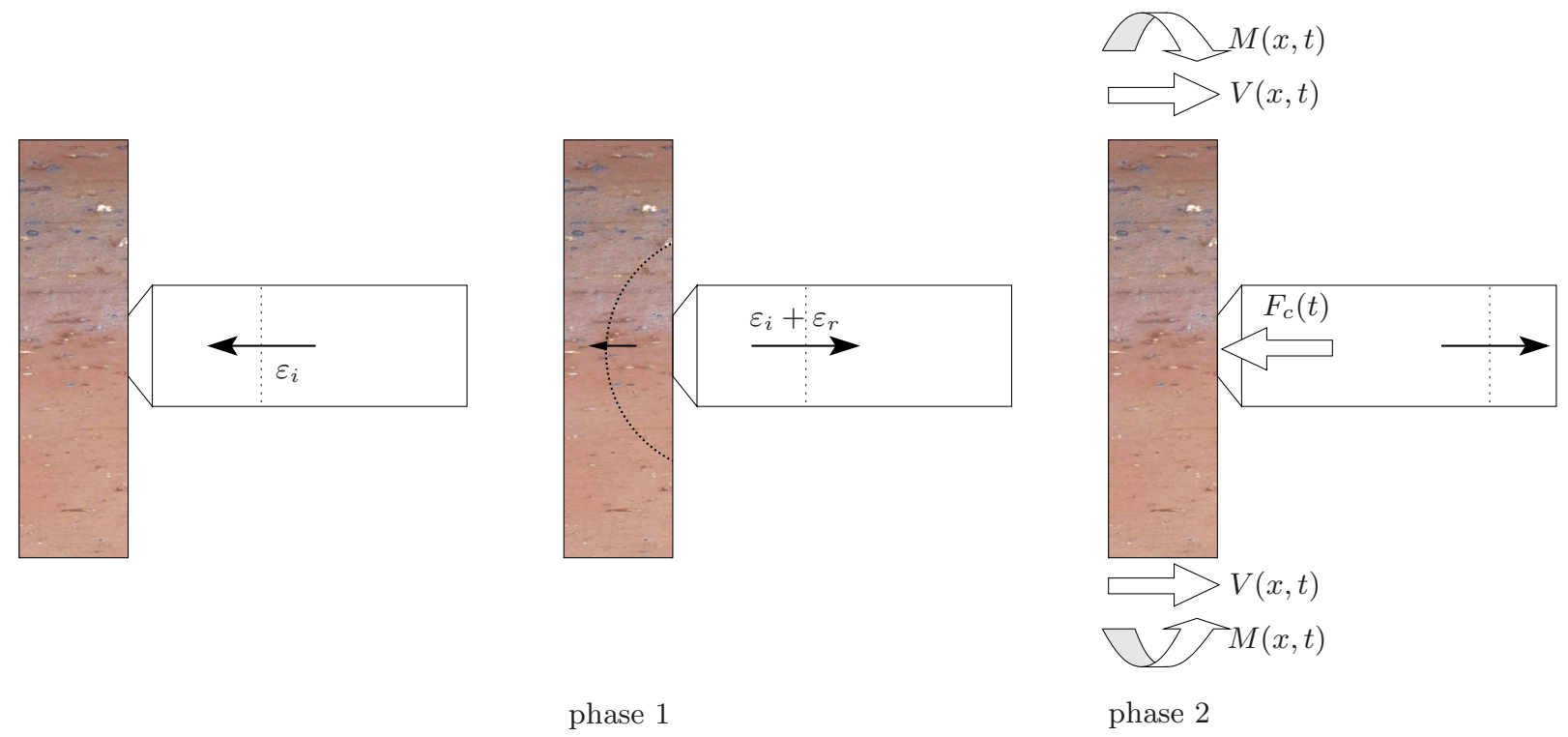

Fig. 4. Different phases observed during an impact test.

force, which, after a short transitory phase, generates a bending state. To describe the mechanical response of the specimen, two phases, or two time scales, are generally considered.

- The first phase consists in considering the first instant following the impact and a zone close to the contact area with the input bar (Fig. 4 - phase 1). The compression wave from the input bar is transmitted and propagates in the specimen. The characteristic time for this phase is the travel time taken by the wave through the transversal dimension of the solid. An order of magnitude for this time is $t_{t}=\frac{a}{C_{p}}$ (where $C_{p}$ is the velocity of $\mathrm{P}$-waves). This time scale is that which is used to represent the phenomenon of spalling when this occurs. For example, in the case of the brick studied, we have $C_{p}=3505 \mathrm{~m} . \mathrm{s}^{-1}, a=0.053 \mathrm{~m}$ and find $t_{t}=15 \times 10^{-6} \mathrm{~s}$.

- The second phase relates to times greater than $t_{t}$ (Fig. 4 - phase 2). At this time scale, the waves are reflected and diffracted several times in the specimen. The motions must be considered on the global scale of the sample and a model representative of its structure must be used. Given the dimensions of our samples, we are considering a beam model.

This model gives a very good estimation of the stresses and strains if the solid is slender: $L \gg a$. In dynamics, this condition is translated by the fact that the beam model can only correctly represent the motions whose wave length $\lambda$ is greater than the transversal dimension of the beam: $\lambda \gg a$.

What appears more specifically in tests on quasibrittle materials is the necessity of considering a third time scale: that associated with the time required for the transversal motions to propagate over a length equal to that of the half-beam and return back to the impact point.
This time is of the magnitude of $t_{f}=\frac{L}{C_{f}}$, where $C_{f}$ represents the velocity of the bending waves. It shall be compared to the test time, or to the sample fracture time $t_{r}$ :

(i) If the time of the bending test is very long before $t_{f}$, equilibrium similar to that obtained statically can be considered. In this case, we observe that the support reaction is equal to $R=\frac{F}{2}$.

(ii) If the time of the bending test is of the same order of magnitude as the time required for the transversal motions to propagate over a length equal to that of the beam, we will note that $R \neq \frac{F}{2}$. The transient motion of the beam must be taken into account in analyzing the test.

(iii) If the time of the bending test is less that the time required for the transversal motions to propagate over a length equal to that of the beam, we will note that $R=0$. The problem is thus the same as if the beam was of infinite length.

Classically, tests performed on metallic or composite materials lead to the first, and sometimes the second, situation being observed. The configuration of the test presented here and the quasi-brittle materials tested are such that the third situation is always observed. The a priori determination of the hypothesis most adapted to a test is not easy. Indeed, the useful parameters are the duration of the test and the velocity of the bending waves, which depend on the wavelength. A lower bound of the time $t_{f}$ can be obtained considering that the bending waves cannot propagate faster than the primary waves: $t_{f} \geq \frac{L}{C_{p}}$. In practice, it is the observation of the fracture that will allow us to specify the test time (noted as $t_{r}$ ). Observing the waves transmitted in the output bars, and in particular the instant of their appearance, will enable us to 


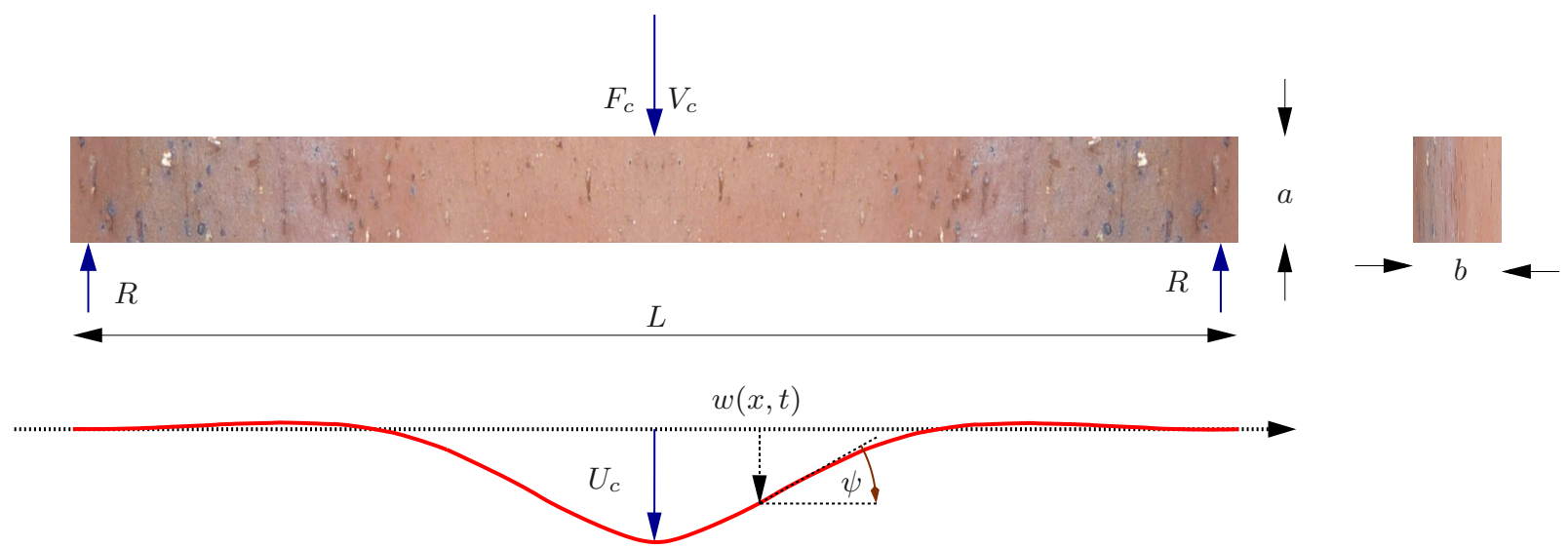

Fig. 5. Euler Bernoulli beam model.

know if the reaction could be felt in the central zone before the fracture. The most appropriate hypothesis is thus deduced to utilize the measurements.

\section{Infinite beam model}

During the first times of the impact, the stress wave does not reach the supports and the situation is equivalent to a one-point bending test. Therefore, in order to make the best possible use of the experimental data during the beginning of the test, it is proposed to consider an infinite Euler-Bernoulli elastic beam (Fig. 5).

The equation governing the transverse displacement $w$ is the following:

$$
\frac{\partial^{4} w}{\partial x^{4}}+4 \alpha^{4} \frac{\partial^{2} w}{\partial t^{2}}=0 \quad \text { where } \quad 4 \alpha^{4}=\frac{\rho S}{E I}
$$

satisfying, as boundary conditions, at the interface bar/specimen:

$$
\begin{aligned}
w(0, t) & =U_{c}(t), \quad \frac{\partial w}{\partial x}(0, t)=\psi(0, t), \\
\frac{\partial^{2} w}{\partial x^{2}}(0, t) & =\frac{M(0, t)}{E I}, \frac{\partial^{3} w}{\partial x^{3}}(0, t)=\frac{F_{c}(t)}{2 E I}
\end{aligned}
$$

At the other end of the beam $(x=+\infty)$, the transverse displacement is zero.

Using the time Laplace transform [14], the transient dynamic elastic response of the test specimen can be expressed in terms of the velocity $V_{c}$ and of the force $F_{c}$ :

$$
\begin{aligned}
w(x, t) & =\int_{0}^{t} G_{1}(t-\tau) \Omega_{1}(x, \tau) \mathrm{d} \tau \\
& -\int_{0}^{t}\left(G_{1}(t-\tau)+G_{2}(t-\tau)\right) \Omega_{2}(x, \tau) \mathrm{d} \tau
\end{aligned}
$$

where

$$
\begin{aligned}
& \Omega_{1}(x, t)=\frac{1}{\sqrt{\pi t}} \cos \left(\frac{\alpha^{2} x^{2}}{2 t}\right), \\
& \Omega_{2}(x, t)=\frac{1}{\sqrt{\pi t}} \sin \left(\frac{\alpha^{2} x^{2}}{2 t}\right)
\end{aligned}
$$

and

$$
G_{1}(t)=\int_{0}^{t} \frac{V_{c}(\tau)}{\sqrt{\pi(t-\tau)}} \mathrm{d} \tau, G_{2}(t)=\int_{0}^{t} \frac{F_{c}(\tau)}{4 E I \alpha^{3}} \mathrm{~d} \tau
$$

The functions that enter into the expression of the displacement are linked to the elementary solutions $\Omega_{1}$ and $\Omega_{2}$, and to the functions $G_{1}$ and $G_{2}$ whose values are calculated from the measurements made. Via the use of (1) and (2), the motion is entirely described from the measurements made on the incident bar.

The beam section rotation, the curvature and thus the bending moment, as well as the shear force are expressed as functions of the transverse displacement:

$$
\begin{aligned}
\psi(x, t) & =\frac{\partial w}{\partial x}(x, t), M(x, t)=E I \frac{\partial^{2} w}{\partial x^{2}}(x, t), \\
V(x, t) & =-E I \frac{\partial^{3} w}{\partial x^{3}}(x, t)
\end{aligned}
$$

Since the behavior of the specimen is assumed to be elastic until the appearance of cracking, the rotation of the cross-section under the impact point remains zero. A coupling relation between the force and the velocity is then obtained:

$$
V_{c}(t)=\frac{1}{2 \eta} \int_{0}^{t} \frac{F_{c}(\tau)}{\sqrt{\pi(t-\tau)}} \mathrm{d} \tau \quad \text { where } \quad \eta=4 E I \alpha^{3}
$$

Using (1) and (2), it can be rewritten as a relation between the incident and reflected waves:

$$
\begin{aligned}
& \varepsilon_{r}(t)=\varepsilon_{i}(t)-\int_{0}^{t} \frac{2 \varepsilon_{i}(\tau)}{\sqrt{\tau_{f}}} \\
& \times\left(\frac{1}{\sqrt{\pi(t-\tau)}}-\frac{1}{\sqrt{\tau_{f}}} e^{\frac{t-\tau}{\tau_{f}}} \operatorname{erfc}\left(\sqrt{\frac{t-\tau}{\tau_{f}}}\right)\right) \mathrm{d} \tau
\end{aligned}
$$

where $\tau_{f}=\left(\frac{2 \eta}{Z_{B}}\right)^{2}$ and $\operatorname{erfc}(t)=\frac{2}{\sqrt{\pi}} \int_{t}^{\infty} e^{-t^{2}} \mathrm{~d} t$ denotes the complementary error function.

During the dynamic bending process the stress state is not homogeneous. The position of the section where 


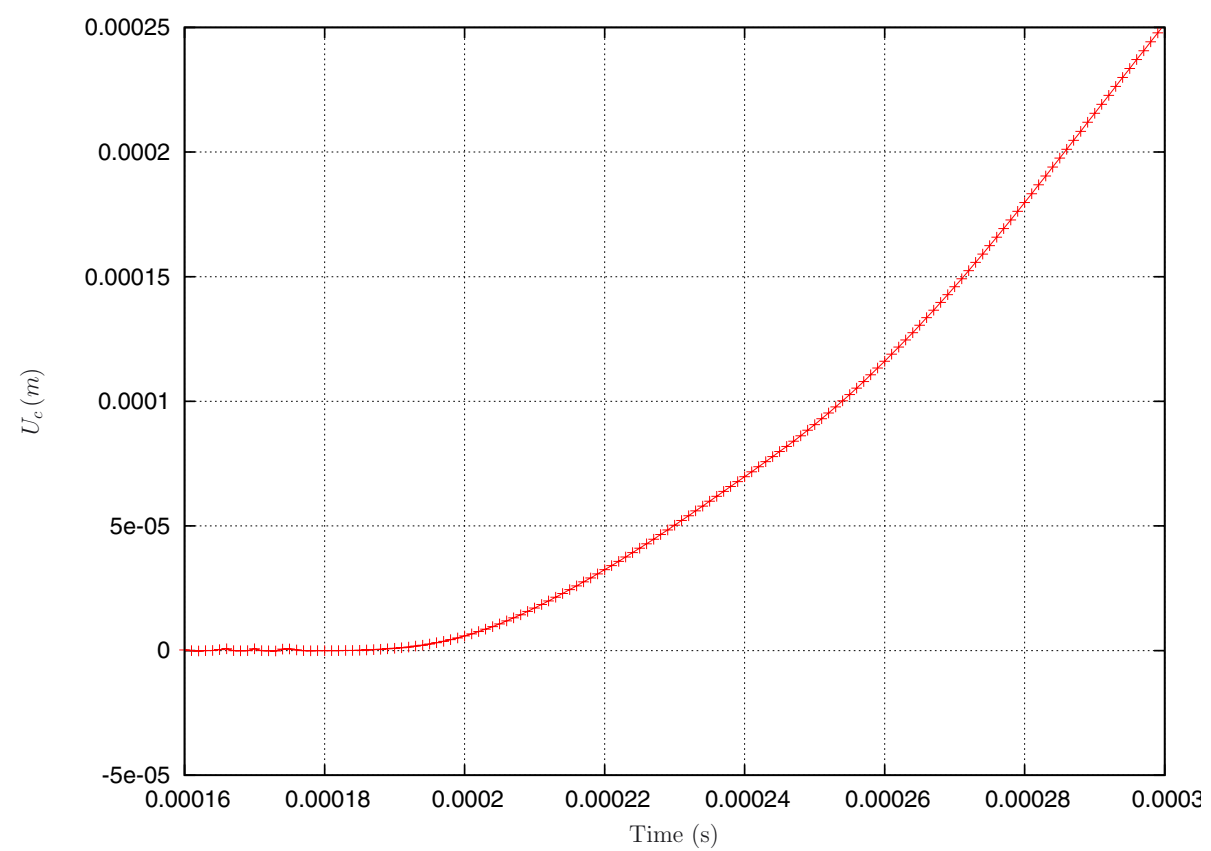

Fig. 6. Displacement evolution at the interface.

the bending moment and thus the tensile stress are maximal depends on the load $F_{c}(t)$ and can vary over time. Nothing allows us to predict, a priori, the zone in which the first fracture will appear. In practice, in the tests performed, the first fracture has always occurred in the middle of the specimen $(x=0)$. Consequently, the strain rate and tensile stress are evaluated in the central section of the specimen and in the most highly strained fiber of the beam:

$$
\begin{gathered}
\dot{\varepsilon}(t)=a \alpha^{2} \dot{V}_{c}(t) \\
\sigma(t)=a \alpha^{2} E V_{c}(t)
\end{gathered}
$$

We can emphasize that contrary to a quasi-static analysis, the maximum tensile stress is proportional to the velocity and not to the displacement.

\section{Finite-element simulations and comparison with infinite beam data processing}

In order to assess the relevance of using an infinite beam model to process short beams experiments, finiteelement simulations are performed. The finite-element code used is Cast3M developed by the Department of Mechanics and Technology of the French Atomic Energy Agency [15]. The simulations were carried out in 2D situations under plane strain state assumptions, since the results obtained in $3 \mathrm{D}$ simulations with coarse mesh were equivalent. The meshing elements used were quadrilaterals with 8 nodes and a quadratic interpolation. Time resolution was performed using the implicit Newmark scheme. We took a very small time step, equivalent to the CourantFriedrichs-Lewy condition, to accurately describe wave propagation. The mesh was refined up to convergence of the static reference calculations. The regular meshing procedure adopted included 4877 nodes and 1560 elements (grid of $20 \times 78$ ). 1D simulations were also carried out using Euler-Bernoulli beam elements and Timoshenko beam elements meshed using the same axial mesh discretization procedure as above.

The input data for the FE solver are either the displacement (Fig. 6) or the force (Fig. 7) at the interface input bar/specimen determined from experimental measurements via (1) and (2).

Since the specimen breaks during the first incident pulse, the force presents a maximum while the displacement shows a continuous increase. The first comparison is done between stress and strain rate in the most tense fiber with imposed displacement as boundary loading condition.

Figures 8 and 9 show the good agreement between values predicted by the explicit approach and finite-element solutions for both the maximum tensile stress and the strain rate. The difference is less than $5 \%$ between the most precise finite-element calculation and the analytical one.

Since the mechanical behavior of the specimen is assumed to be elastic-fragile, finite-element and explicit solutions are valid only during the elastic phase. As a consequence, the onset of fracture is defined, in finite-element simulations, as the time at which the force controlled and displacement controlled solutions disagree. Neglecting the small time delay, we can consider from Figures 10 and 11 that it is concomitant with the instant at which the tensile stress presents a maximum.

For the explicit infinite beam model, Figures 8 and 9 were obtained with the experimental incident $\varepsilon_{i}(t)$ and 


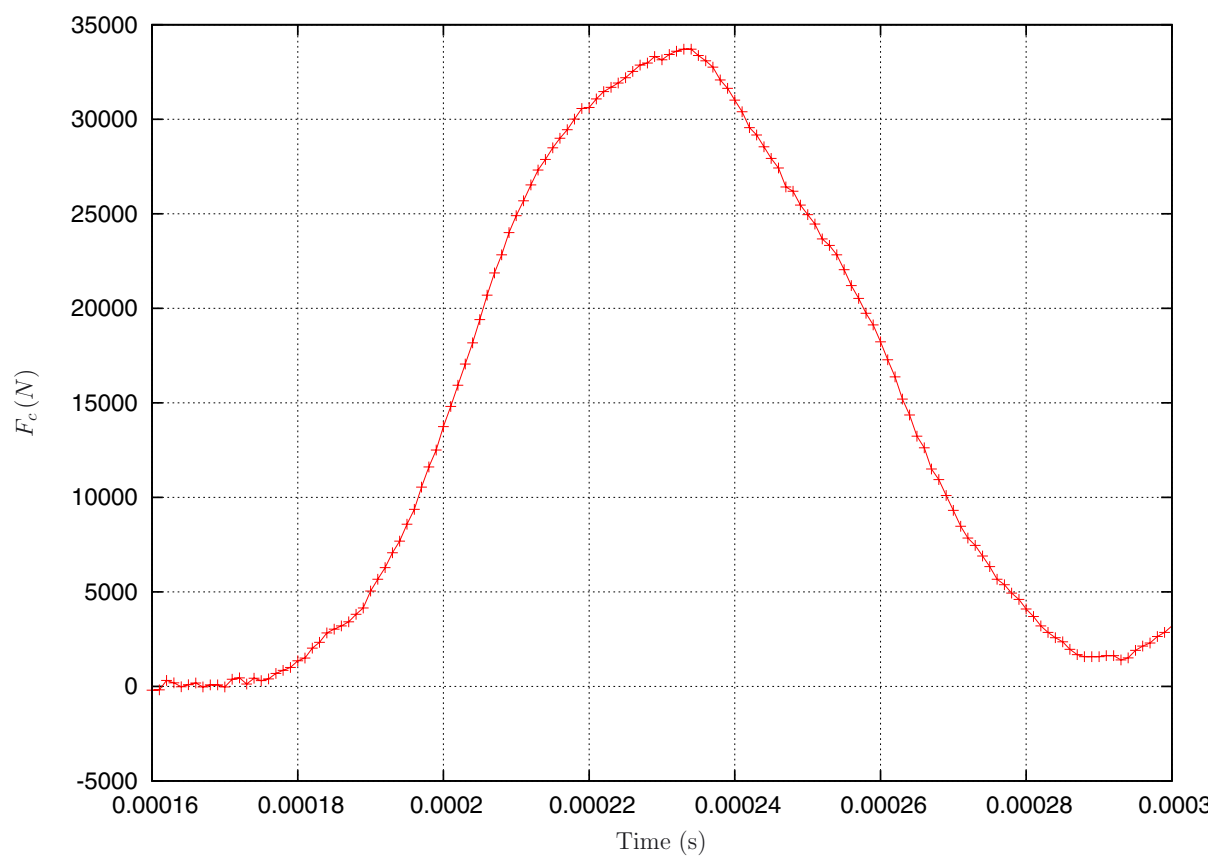

Fig. 7. Force evolution at the interface.

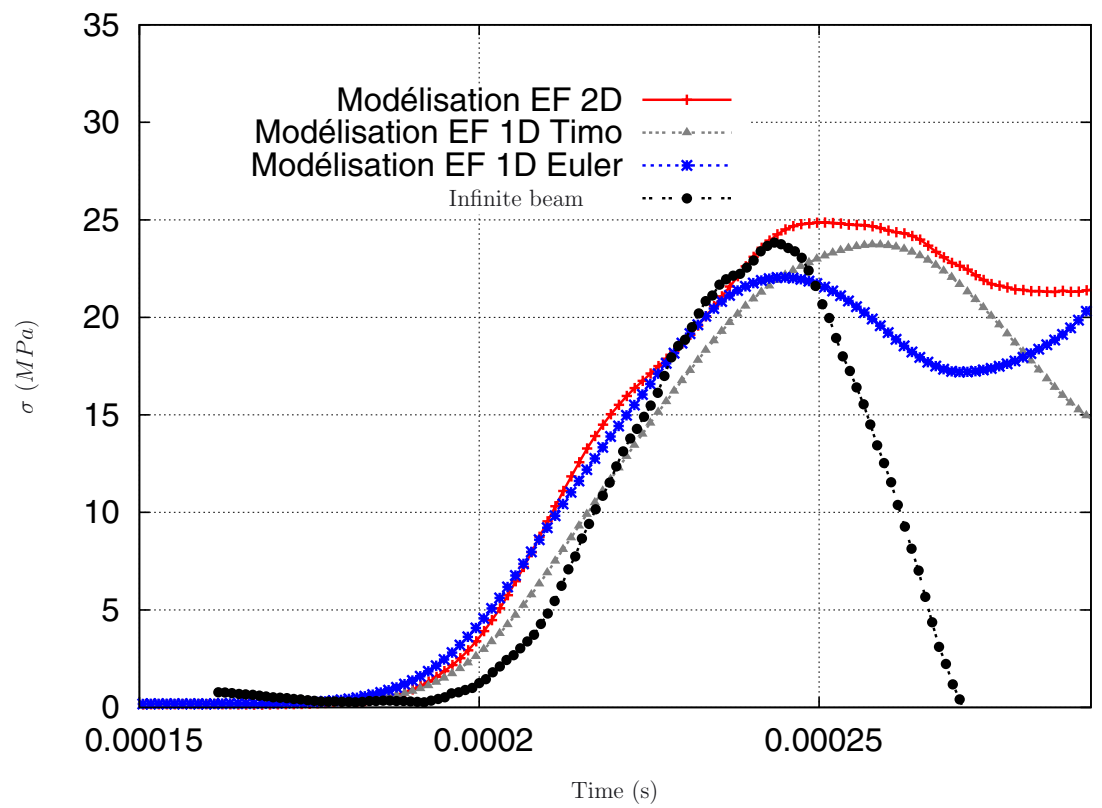

Fig. 8. Maximum tensile stress in the specimen.

reflected $\varepsilon_{r}(t)$ waves. The elastic response of the specimen can also be simulated by using the measured incident strain wave as input and computing a simulated reflected wave with Equation (11):

$$
\begin{aligned}
& \varepsilon_{\mathbf{r}}^{\operatorname{simu}}(t)=\varepsilon_{i}^{\exp }(t)-\int_{0}^{t} \frac{2 \varepsilon_{i}^{\exp }(\tau)}{\sqrt{\tau_{f}}} \\
& \times\left(\frac{1}{\sqrt{\pi(t-\tau)}}-\frac{1}{\sqrt{\tau_{f}}} e^{\frac{t-\tau}{\tau_{f}}} \operatorname{erfc}\left(\sqrt{\frac{t-\tau}{\tau_{f}}}\right)\right) \mathrm{d} \tau
\end{aligned}
$$

The associated strain rate and stress read:

$$
\begin{aligned}
\dot{\varepsilon}^{\mathrm{simu}}(t) & =a \alpha^{2} C_{B}\left(\dot{\varepsilon}_{\mathbf{r}}^{\mathrm{simu}}(t)-\dot{\varepsilon}_{i}^{\exp }(t)\right) \\
\sigma^{\operatorname{simu}}(t) & =a \alpha^{2} E C_{B}\left(\varepsilon_{\mathbf{r}}^{\operatorname{simu}}(t)-\varepsilon_{i}^{\exp }(t)\right)
\end{aligned}
$$

The unset of fracture is also found to be simultaneous with the maximum of the tensile stress.

The time to fracture is $t_{r} \approx 75 \times 10^{-6} \mathrm{~s}$. A first estimation, based on $\mathrm{P}$-waves, of the minimum time required by bending waves to reach support and return back to 


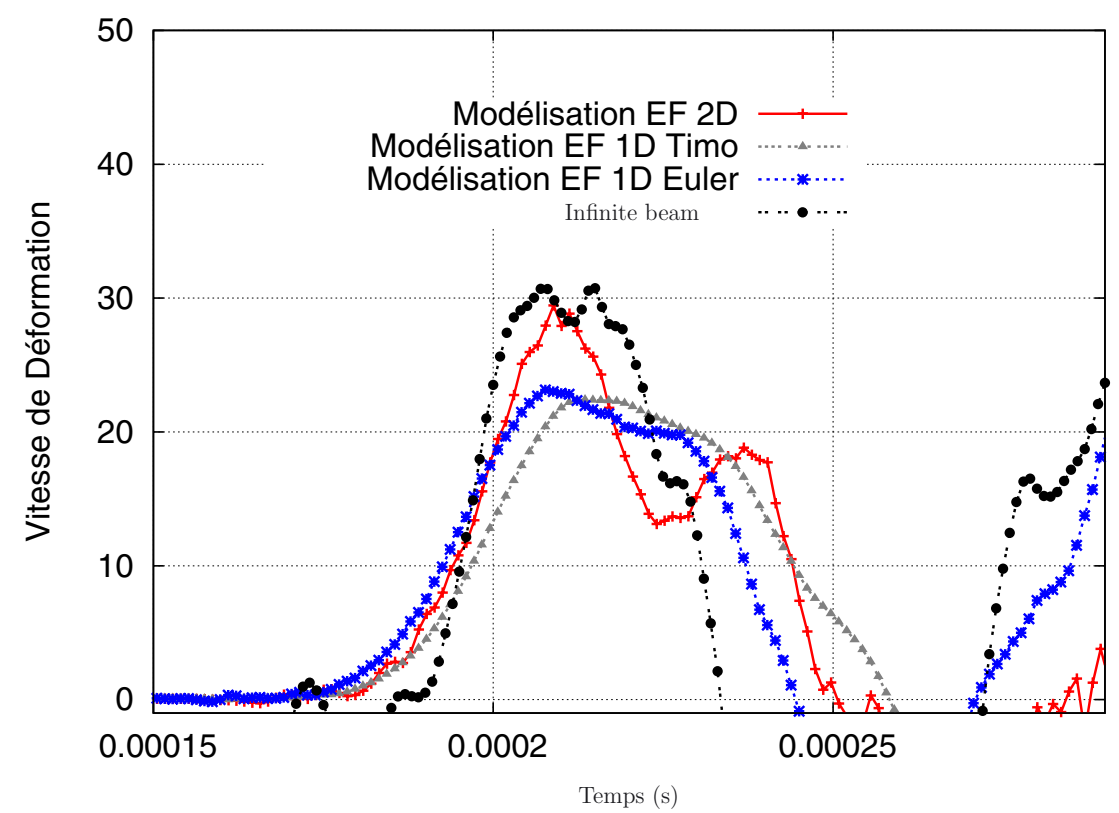

Fig. 9. Maximum strain rate in the specimen.

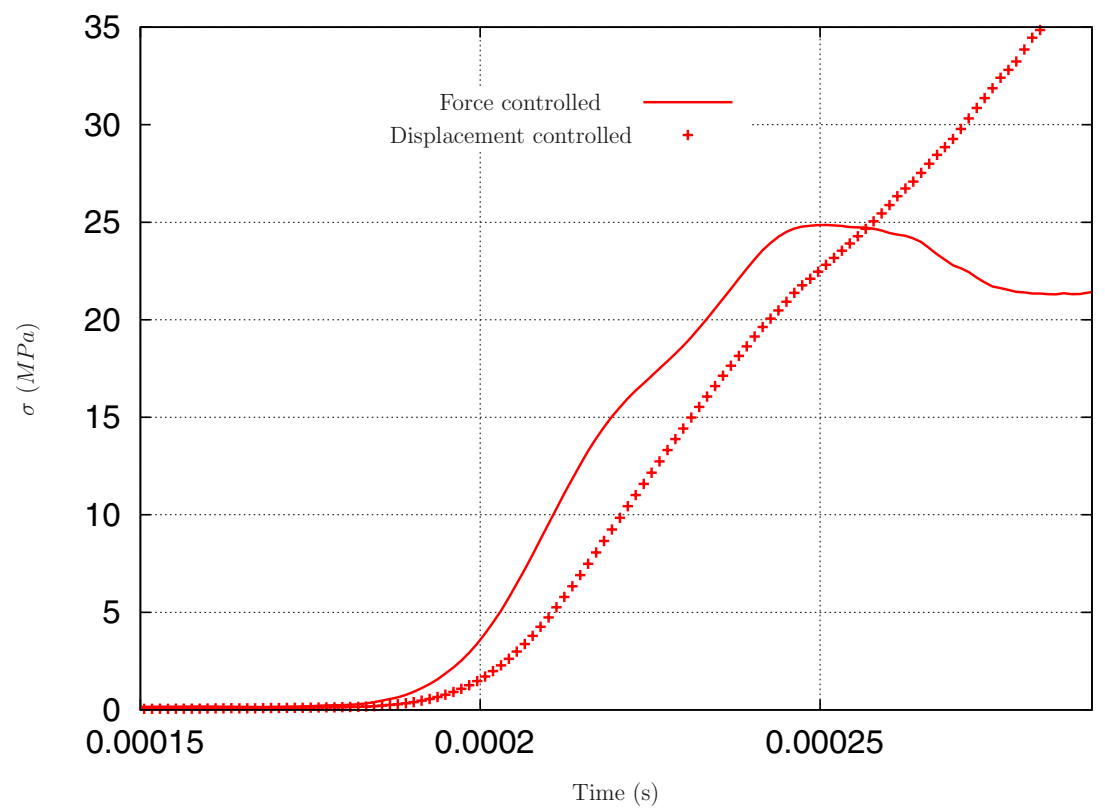

Fig. 10. Maximal tensile stress in force and displacement controlled 2D FE.

impact point gives: $t_{f}=\frac{L}{C_{p}}=60 \times 10^{-6} \mathrm{~s}$. This value is found lower than $t_{r}$ which could have lead us to conclude that the infinite beam model is irrelevant. In fact, finite-element simulations give us the real time at which support reaction appear $\approx 115 \times 10^{-6} \mathrm{~s}$ which is found greater than $t_{r}$.

Finite-element simulations enabled us to demonstrate that an analytical approach based on an infinite beam model remains remarkably accurate to evaluate the dynamic flexural strength of a brittle material with a short specimen. For the considered test, whatever the data processing procedure, finite-element or explicit calculations, it is found that the mechanical strength has a value of $\approx 25 \mathrm{MPa}$ linked with a maximum strain rate of $\approx 30 \mathrm{~s}^{-1}$ which gives a dynamic increase factor around 4.5.

\section{SHPB bending test results}

In order to be consistant with dynamic splitting tests and spalling tests, the variation of the dynamic tensile 


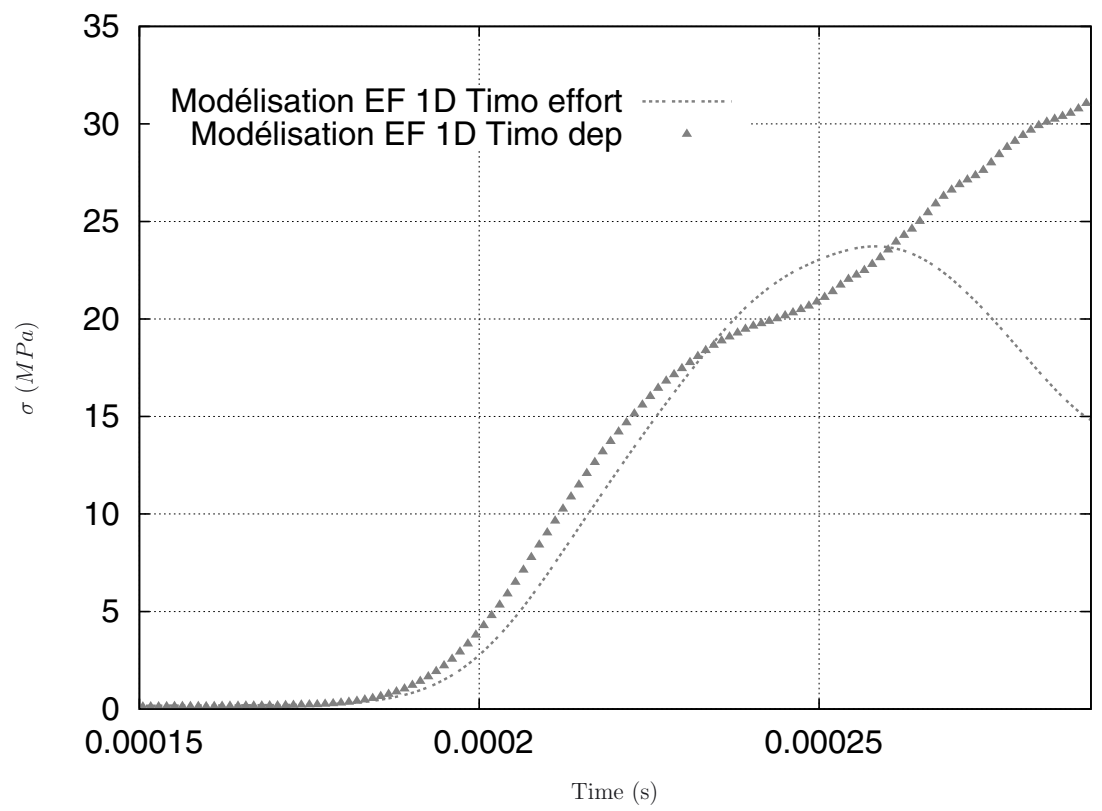

Fig. 11. Maximal tensile stress in force and displacement controlled 1D Timoshenko FE.

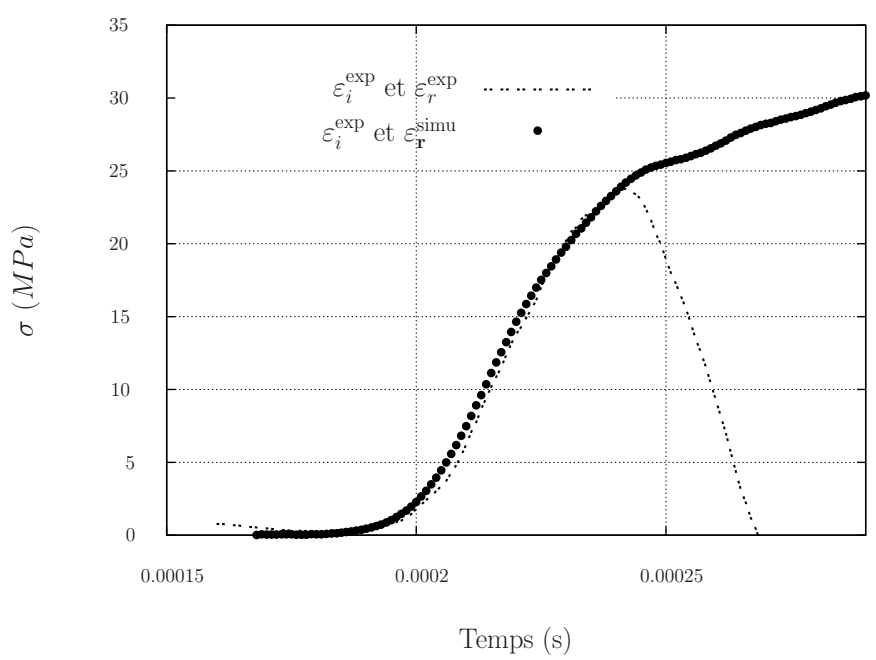

Fig. 12. Maximal tensile stress: semi-infinite beam model.

Table 3. Dynamic increase factor as a function of the nominal strain rate for brick specimen.

\begin{tabular}{ccccccc}
\hline$\dot{\varepsilon}$ & 6 & 20 & 22 & 28 & 70 & 86 \\
\hline DIF & 2 & 4.2 & 4.2 & 4.5 & 5.8 & 7.45 \\
\hline
\end{tabular}

strength is expressed as a function of the nominal strain rate. This nominal strain rate is defined as the peak strain divided by the time interval between the start of loading and specimen failure. The results for brick and concrete are summarized in Tables 3 and 4 and reported in Figure 14 and compared to other experimental data from the literature.

As expected, for the two different quasi-brittle materials, a dynamic tensile enhancement is observed.
Table 4. Dynamic increase factor as a function of the nominal strain rate for concrete specimen.

\begin{tabular}{cccccccc}
\hline$\dot{\varepsilon}$ & 9.5 & 15 & 29 & 48 & 51 & 62 & 67 \\
\hline DIF & 1.9 & 2.8 & 3.3 & 6.4 & 6.9 & 7.7 & 8.1 \\
\hline
\end{tabular}

The results are in agreement with those obtained with different experimental techniques and different concretelike materials. We can also note that our experimental device enables strain rates of about $100 \mathrm{~s}^{-1}$ to be obtained. It is, however, difficult to make further observations since there is no uniqueness of the concrete material. The two classically defined domains $[26,30]$ are found. The first domain, which concerns strain rates of less than $1 \mathrm{~s}^{-1}$ is that where the relative mechanical strength varies little as a function of the strain rate (less than 2). In the second domain, the relative strength increases significantly and can exceed a value of 5 . Different physical phenomena are classically quoted to explain this dependency of strength to the strain rate for this kind of materials. The presence of free water in the porosities of the material can produce an effect of this type [31], however, the materials tested here are dry. Another explanation is linked to the brittle, non-homogeneous nature of these materials for which the mechanical strength has a randomness that can be approached by the Weibull theory [32].

\section{Conclusion and future work}

In this paper, an analytical procedure to process three point bending test using Hopkinson bars on quasibrittle materials is presented and applied. This method is adapted to the case where the fracture occurs before the motion following the impact is propagated to the supports 


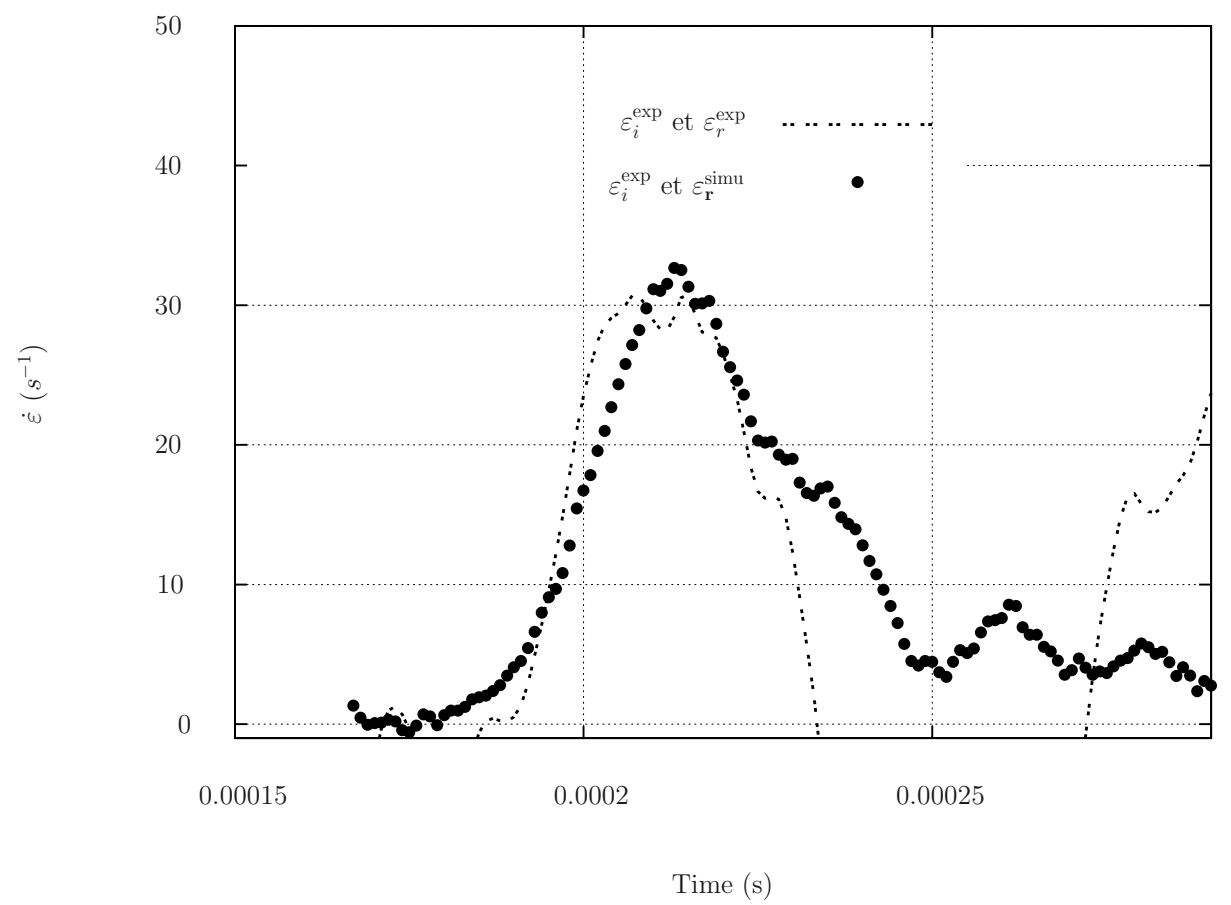

Fig. 13. Maximal strain rate: semi-infinite beam model.

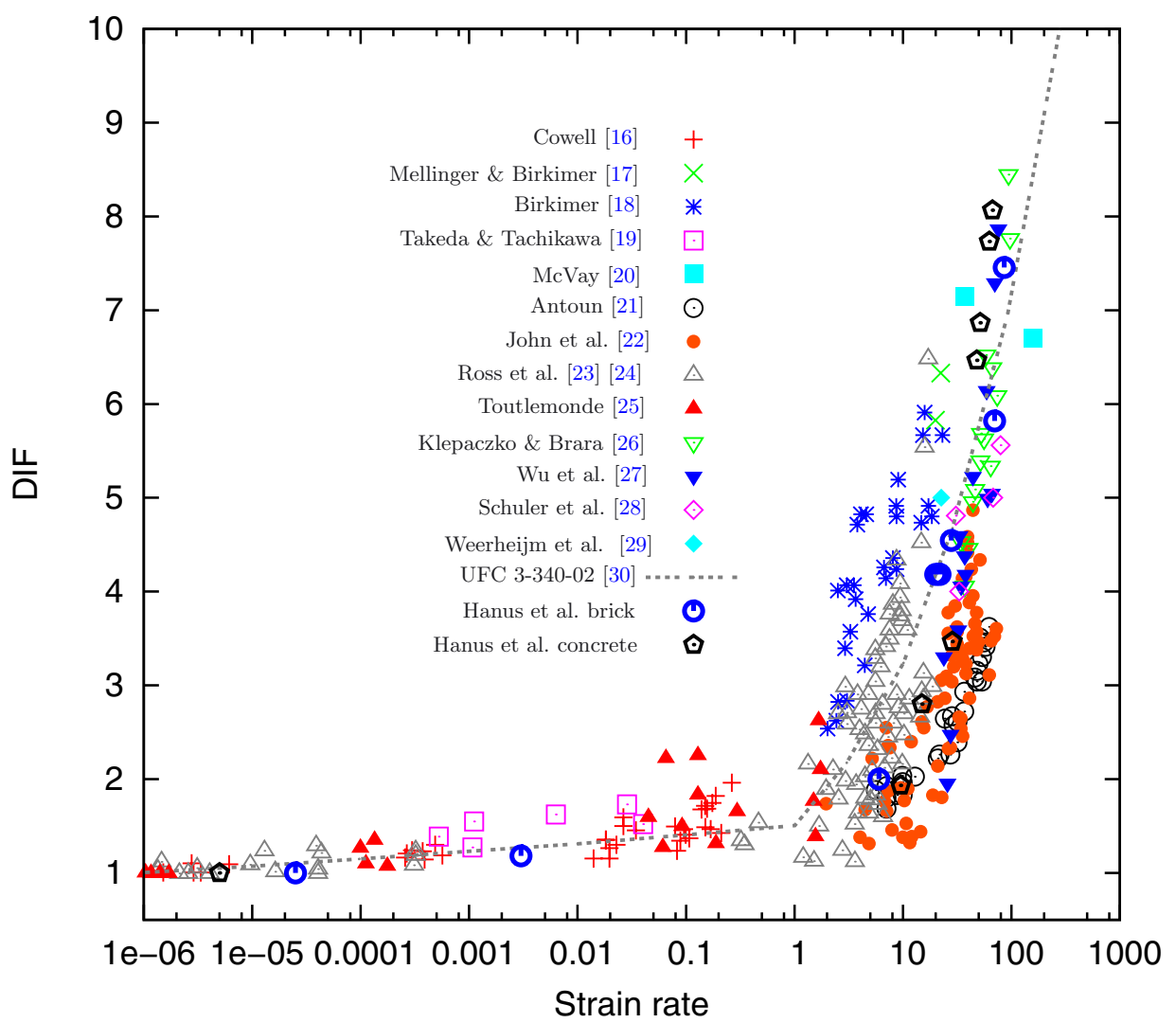

Fig. 14. Strain rate dependance of the tensile strength dynamic increase factor - results from different sources compared with the present study. 
and return back to the impact point. It seems well-suited to study the relative strength increase with strain rate. The results obtained with real experimental data have been compared with those of finite-element simulations. The good agreement observed shows that this approach, previously developed for slender and thin specimen [7], can be applied to a normalized short specimen. This study is a new step in the development of a simple identification procedure of flexural dynamic strength consistent with the classical one used in static analysis satisfying standard recommendations $[8,9]$. Nevertheless, the number of tests performed remains limited so that other experiments are required. Further developments will also relate to the use of redundant information to confirm the validity of the proposed procedure. This can be done either by instrumenting the specimen with strain and fracture gauges or by taking advantage of recent advances in high speed full-field measurements with digital image correlation techniques [33].

Acknowledgements. The authors would like to thank French National Research Agency (ANR) (in the framework of the VULCAIN ANR-07-PGCU) and Région Centre (in the framework of IMFRA2 APR-2012) for supporting this project. Authors acknowledge the experimental support from L. Bouazaoui, O. Pennetier and E. Mennesson.

\section{References}

[1] L.J. Malvar, J.E Crawford, Dynamic increase factors for concrete, In 28th Department of defense explosives safety seminar, Orlando, FL, 1998

[2] J.E. Field, S.M. Walley, W.G. Proud, H.T. Goldrein, C.R. Siviour, Review of experimental techniques for high rate deformation and shock studies, Int. J. Impact Eng. 30 (2004) 725-775

[3] T. George, Gray III, Classic split Hopkinson bar testing, ASM Int. 8 (2000) 462-476

[4] J.W. Tedesco, C.A. Ross, S.T. Kuennen, Experimental and numerical analysis of high strain rate splitting-tensile tests, ACI Mater. J. 90 (1993) 162-169

[5] B. Erzar, P. Forquin, An experimental method to determine the tensile strength of concrete at high rates of strain, Exp. Mech. 50 (2010) 941-955

[6] F. Jiang, K.S. Vecchio, Hopkinson bar loaded fracture experimental technique: A critical review of dynamic fracture toughness tests, Appl. Mech. Rev. 62 (2009) 060802

[7] F. Delvare, J.L. Hanus, P. Bailly, A non-equilibrium approach to processing Hopkinson bar bending test data: Application to quasi-brittle materials, Int. J. Impact Eng. 37 (2010) 1170-1179

[8] NF EN 12390-1, Testing hardened concrete - Part 1: Shape, dimensions and other requirements for specimens and moulds, AFNOR, 1999

[9] NF EN 12390-5, Testing hardened concrete - Part 5: Flexural strength of test specimen, Afnor, 2001

[10] T. Yokoyama, K. Kishida, A novel impact three-point bend test method for determining dynamic fractureinitiation toughness, Exp. Mech. 29 (1989) 188-194
[11] G. Gary, J.R. Klepaczko, H. Zhao, Correction de dispersion pour l'analyse des petites déformations aux barres de Hopkinson, In Colloque C3, supplément au J. Phys. III, Vol. 1, 1991, pp. 403-410

[12] H. Zhao, G. Gary, On the use of SHPB techniques to determine the dynamic behavior of materials in the range of small strains, Int. J. Solids Struct. 33 (1996) 3363-3375

[13] D. Mohr, G. Gary, B. Lundberg, Evaluation of stressstrain curve estimates in dynamic experiments, Int. J. Impact Eng. 37 (2010) 161-169

[14] V. Ditkine, A. Proudnikov, Calcul opérationnel, Editions MIR, Moscou, 1979

[15] CASTEM 2000, Code de calcul pour l'analyse de structures par la méthode des éléments finis. Guide d'utilisation, Commissariat à l'Énergie Atomique, DEN/DM2S/SEMT/LM2S, Gif-sur-Yvette, France, 1998

[16] W.L. Cowell, Dynamic properties of plain Portland cement concrete, Technical Report R447, Naval Civil Engineering Laboratory, Port Hueneme, CA, 1966

[17] F.M. Mellinger, D.L. Birkimer, Measurement of stress and strain on cylindrical test specimens of rock and concrete under impact loading, Technical Report 4-46, U.S. Army Corps of Engineers, Ohio River Division Laboratories, Cincinnati, Ohio, 1966

[18] D.L. Birkimer, Critical Normal Fracture Strain of Portland Cement Concrete, Ph.D. thesis, University of Cincinnati, 1968

[19] J. Takeda, H. Tachikawa, Deformation and fracture of concrete subjected to dynamic load, In Mechanical Behavior of Materials, volume IV, Kyoto, 1971

[20] M.K. McVay, Spall damage of concrete structures, Technical Report SL-88-22, U.S. Army Corps of Engineers, Waterways Experiment Station, Vicksburg, MS, 1988

[21] T.H. Antoun, Constitutive/failure model for the static and dynamic behaviors of concrete incorporating effects of damage and anisotropy, Ph.D. thesis, University of Dayton, Ohio, 1991

[22] R. John, T. Antoun, A.M. Rajendran, Effect of strain rate and size on tensile strength of concrete. In APS Topical Conference on Shock Compression of Condensed Matter, Williamsburg, VA, 1992, pp. 501-504

[23] C.A. Ross, P.Y. Thompson, J.W. Tedesco, SplitHopkinson pressure-bar tests on concrete and mortar in tension and compression, ACI Mater. J. 86 (1989) 475481

[24] P. Rossi, F. Toutlemonde, Effect of loading rate on the tensile behavior of concrete: Description of the physical mechanisms, Mater. Struct. 29 (1996) 116-118

[25] F. Toutlemonde, Résistance au choc des structures en béton - Du comportement du matériau au calcul des ouvrages, Ph.D. thesis, Laboratoire Central des Ponts et Chausseés, Paris, France, 1995

[26] J. Klepaczko, A. Brara, An experimental method for dynamic tensile testing of concrete by spalling, Int. I. Impact Eng. 25 (2001) 387-409

[27] H. Wu, Q. Zhang, F. Huang, Q. Jin, Experimental and numerical investigation on the dynamic tensile strength of concrete, Int. J. Impact Eng. 32 (2005) 605-617 
[28] H. Schuler, C. Mayrhofer, K. Thoma, Spall experiments for the measurement of the tensile strength and fracture energy of concrete at high strain rates, Int. J. Impact Eng. 32 (2006) 1635-1650

[29] J. Weerheijm, J.C.A.M. Van Doormaal, Tensile failure of concrete at high loading rates: New test data on strength and fracture energy from instrumented spalling tests, Int. J. Impact Eng. 34 (2007) 609-626

[30] UFC-340-02, Unified facilities criteria 3-340-02, structures to resist the effects of accidental explosions, US Department of Defense, Washington, DC, USA, 2008
[31] P. Rossi, Influence of cracking in the presence of freewater on the mechanical behaviour of concrete, Magazine Concrete Res. 43 (1991) 53-57

[32] F. Hild, C. Denoual, P. Forquin, X. Brager, On the probabilistic-deterministic transition involved in a fragmentation process of brittle materials, Comput. Struct. 81 (2005) 1241-1253

[33] F. Pierron, M. Sutton, V. Tiwari, Ultra high speed DIC and virtual fields method analysis of a three point bending impact test on an aluminium bar, Experim. Mech. 51 (2011) 537-563 